\title{
Ultrafast Aggregation-Induced Tunable Emission Enhancement in a Benzothiadiazole-Based Fluorescent MOF Linker
}

Luis Gutiérrez-Arzaluz, ${ }^{\S, a}$ Issatay Nadinov, ${ }^{\S}$ a George Healing, §.a Justyna Czaban-Jóźwiak, a,b Jiangtao Jia, ${ }^{\text {a,b }}$ Zhiyuan Huang, ${ }^{\text {a,b }}$ Yan Zhao, ${ }^{c}$ Osama Shekhah, ${ }^{\text {a,b }}$ Kirk S. Schanze, ${ }^{c}$ Mohamed Eddaoudi*,a,b Omar F. Mohammed $^{\mathrm{a}, *}$

${ }^{a}$ King Abdullah University of Science and Technology (KAUST), Advanced Membranes and Porous Materials (AMPM) Center, Physical Sciences and Engineering Division (PSE), Thuwal 23955-6900, Kingdom of Saudi Arabia

${ }^{\mathrm{b}}$ Functional Materials Design, Discovery and Development Research Group (FMD ${ }^{3}$ ), King Abdullah University of Science and Technology (KAUST), Thuwal 23955-6900, Kingdom of Saudi Arabia

${ }^{\mathrm{c}}$ Department of Chemistry, University of Texas at San Antonio, San Antonio, Texas 78249, United States

$\S$ These authors contributed equally

\section{Contents}

Detailed Synthetic Procedures ........................................................................................

Steady-State and Time-resolved Spectroscopy ............................................................

Time-Dependent Density Functional Theory Calculations …..............................................

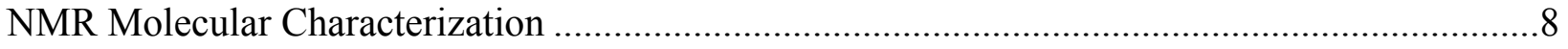




\section{Detailed Synthetic Procedures}

The organic ligands used in this study were prepared as outlined in the following pages. All other reagents were obtained from commercial sources and used without further purification. 1H NMR and ${ }^{13} \mathrm{C}$ NMR spectra were recorded on a Bruker Advance III 400, and $500 \mathrm{MHz}$ instruments. Chemical shifts for $1 \mathrm{H}$ NMR spectra are reported in $\mathrm{ppm}(\delta$, relative to TMS) using DMSO residual peak $(\delta=2.50 \mathrm{ppm})$ in DMSO- $\mathrm{d}_{6}$ as an internal standard. They are also reported for ${ }^{13} \mathrm{C}$ NMR spectra solvent peaks at $39.52 \mathrm{ppm}$, and for solutions in $\mathrm{CDCl}_{3}$ solvent peaks at 7.26 and 77.16 ppm, respectively.

Diethyl 4,4'-(benzo[c][1,2,5]thiadiazole-4,7-diylbis(ethyne-2,1-diyl))dibenzoate (Figure S7, S8): Dry Schlenk flask was charged with 4,7-dibromobenzo[c][1,2,5]thiadiazole (0.59 g, 1 Eq, 2.0 $\mathrm{mmol}$ ), ethyl 4-ethynylbenzoate (909.0 mg, 2.6 Eq, $5.22 \mathrm{mmol}), \mathrm{Pd}\left(\mathrm{PPh}_{3}\right)_{2} \mathrm{Cl}_{2}(70.44 \mathrm{mg}, 0.05 \mathrm{Eq}$, $100.4 \mu \mathrm{mol})$, copper(I) iodide (38.22 mg, $0.1 \mathrm{Eq}, 200.7 \mu \mathrm{mol})$, triphenylphosphine (210.6 mg, 0.4 $\mathrm{Eq}, 802.8 \mu \mathrm{mol})$, anhydrous $\mathrm{DMF}(10 \mathrm{~mL})$ and anhydrous $\mathrm{Et}_{3} \mathrm{~N}(5 \mathrm{~mL})$. The mixture was argonated and sealed with septa. This mixture was stirred at reflux temperature for $48 \mathrm{~h}$. Reaction mixture was cooled to room temperature, during which a precipitate appeared. The mixture was filtered to collect the precipitate, and it washed with THF. Diethyl 4,4'-(benzo[c][1,2,5]thiadiazole4,7-diylbis(ethyne-2,1-diyl))dibenzoate ( $0.845 \mathrm{~g}, 1.76 \mathrm{mmol}, 88 \%$ ) was obtained as a yellow solid with the following: $1 \mathrm{H} \mathrm{NMR} \mathrm{(500} \mathrm{MHz,} \mathrm{CDCl3)} \delta 8.12-8.04(\mathrm{~m}, 4 \mathrm{H}), 7.84(\mathrm{~s}, 2 \mathrm{H}), 7.77-7.70$ (m, 4H), $4.41(\mathrm{q}, \mathrm{J}=7.1 \mathrm{~Hz}, 4 \mathrm{H}), 1.42(\mathrm{t}, \mathrm{J}=7.1 \mathrm{~Hz}, 6 \mathrm{H}) \mathrm{ppm} ;{ }^{13} \mathrm{C} \mathrm{NMR}\left(126 \mathrm{MHz}, \mathrm{CDCl}_{3}\right) \delta$ $166.1,154.4,132.9,132.0,130.8,129.7,127.0,117.3,96.9,87.9,61.4,14.5 \mathrm{ppm}$.

4,4'-(benzo[c] $[1,2,5]$ thiadiazole-4,7-diylbis(ethyne-2,1-diyl))dibenzoic acid (Scheme 1, Figure S9, S10): Diethyl 4,4'-(benzo[c][1,2,5]thiadiazole-4,7-diylbis(ethyne-2,1-diyl))dibenzoate $(0.740 \mathrm{~g}, 1 \mathrm{Eq}, 1.54 \mathrm{mmol})$ was dissolved in $50 \mathrm{~mL} \mathrm{THF} / \mathrm{MeOH}(1 / 1)$, and $2 \mathrm{~N} \mathrm{LiOH}(738 \mathrm{mg}$, $15.4 \mathrm{~mL}, 30.8 \mathrm{mmol}$ ) was added. The reaction was stirred at RT for $18 \mathrm{~h}$. The mixture was concentrated, diluted with DI water $(50 \mathrm{~mL})$ and washed with EtOAc $(2 \times 40 \mathrm{~mL}$, discarded). The aqueous phase was acidified with $2 \mathrm{~N} \mathrm{HCl}$, a light precipitate was collected by filtration, washed thoroughly with DI $\mathrm{H}_{2} \mathrm{O}$, and dried on suction overnight. 4,4'-(benzo[c] [1,2,5]thiadiazole-4,7diylbis(ethyne-2,1-diyl))dibenzoic acid (0.640 g, $1.51 \mathrm{mmol}, 98 \%$ ) was obtained as a yellow solid with the following: ${ }^{1} \mathrm{H}$ NMR (500 MHz, DMSO-d $\left.{ }_{6}\right) \delta 8.03(\mathrm{~d}, \mathrm{~J}=8.7 \mathrm{~Hz}, 6 \mathrm{H}), 7.77(\mathrm{~d}, \mathrm{~J}=7.7 \mathrm{~Hz}$, 
4H) ppm; ${ }^{13} \mathrm{C}$ NMR (126 MHz, DMSO-d6) $\delta 166.7,153.7,133.3,131.8,131.7,129.8,125.7$, $116.1,96.2,87.9 \mathrm{ppm}$.

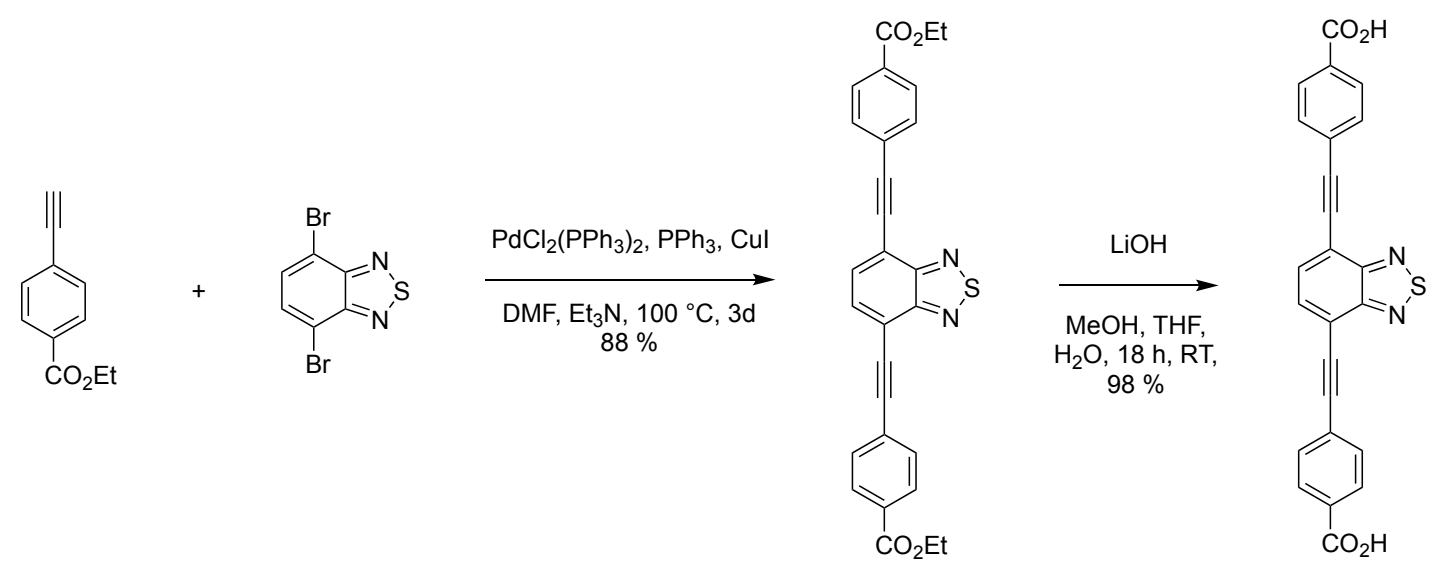

Scheme S1. Synthetic route for AC-TDZ.

Diethyl 4,4'-((1H-benzo[d] imidazole-4,7-diyl)bis(ethyne-2,1-diyl))dibenzoate (Figure S11, S12): Dry Schlenk flask was charged with 4,7-dibromo-1H-benzo[d]imidazole $(0.500 \mathrm{~g}, 1 \mathrm{Eq}$, $1.81 \mathrm{mmol})$, ethyl 4-ethynylbenzoate (821 mg, $2.6 \mathrm{Eq}, 4.71 \mathrm{mmol}), \mathrm{Pd}\left(\mathrm{PPh}_{3}\right)_{2} \mathrm{Cl}_{2}(63.6 \mathrm{mg}, 0.05$ Eq, $90.6 \mu \mathrm{mol})$, copper(I) iodide (34.5 mg, $0.1 \mathrm{Eq}, 181 \mu \mathrm{mol})$, triphenylphosphine (190 mg, 0.4 Eq, $725 \mu \mathrm{mol})$, anhydrous DMF $(10 \mathrm{~mL})$ and anhydrous $\mathrm{Et}_{3} \mathrm{~N}(5 \mathrm{~mL})$. The mixture was argonated and sealed with septa. This mixture was stirred at reflux temperature for $48 \mathrm{~h}$. Reaction mixture was cooled to room temperature, during which a precipitate appeared. The mixture was filtered to collect the precipitate, and washed with THF. Diethyl 4,4'-((1H-benzo[d]imidazole-4,7diyl)bis(ethyne-2,1-diyl))dibenzoate $(0.200 \mathrm{~g}, 432 \mu \mathrm{mol}, 24 \%)$ was obtained as a yellow solid with the following: ${ }^{1} \mathrm{H}$ NMR (500 MHz, DMSO-d $\left.{ }_{6}\right) \delta 8.48(\mathrm{~s}, 1 \mathrm{H}), 8.04(\mathrm{~d}, \mathrm{~J}=8.0 \mathrm{~Hz}, 4 \mathrm{H}), 7.81$ (d, J = 34.7 Hz, 5H), 7.50 (s, 2H), 4.35 (q, J = $7.1 \mathrm{~Hz}, 4 \mathrm{H}), 1.35$ (t, J = 7.1 Hz, 6H) ppm; ${ }^{13} \mathrm{C}$ NMR $\left(126 \mathrm{MHz}, \mathrm{DMSO}-\mathrm{d}_{6}\right) \delta 165.1,143.8,131.8,129.7,129.4,125.7,61.0,14.6 \mathrm{ppm}$.

4,4'-((1H-benzo[d] imidazole-4,7-diyl)bis(ethyne-2,1-diyl))dibenzoic acid (Scheme 2, Figure S12, S14): Diethyl 4,4'-((1H-benzo[d]imidazole-4,7-diyl)bis(ethyne-2,1-diyl))dibenzoate (0.200 g, $1 \mathrm{Eq}, 432 \mu \mathrm{mol})$ was dissolved in $50 \mathrm{~mL}$ THF/MeOH (1/1), and 2N LiOH (104 mg, $2.16 \mathrm{~mL}$, $4.32 \mathrm{mmol}$ ) was added. The reaction was stirred at RT for $18 \mathrm{~h}$. The mixture was concentrated, diluted with DI water $(50 \mathrm{~mL})$ and washed with EtOAc $(2 \times 40 \mathrm{~mL}$, discarded $)$. The aqueous phase was acidified with $2 \mathrm{~N} \mathrm{HCl}$. A light precipitate was collected by filtration, washed thoroughly with DI H2O, and dried on suction overnight. 4,4'-((1H-benzo[d]imidazole-4,7-diyl)bis(ethyne-2,1- 
diyl))dibenzoic acid ( $0.173 \mathrm{~g}, 426 \mu \mathrm{mol}, 98 \%$ ) was obtained as a yellow solid with the following: 1H NMR (500 MHz, DMSO-d6) $\delta 9.10(\mathrm{~s}, 1 \mathrm{H}), 8.03$ (d, J = 8.0 Hz, 4H), 7.84 (d, J = 8.0 Hz, 4H), 7.63 (s, 2H) ppm; 13C NMR (126 MHz, DMSO-d6) $\delta$ 166.7, 143.4, 135.9, 131.9, 131.0, 129.6, $127.3,126.3,110.2,95.1,87.5 \mathrm{ppm}$.

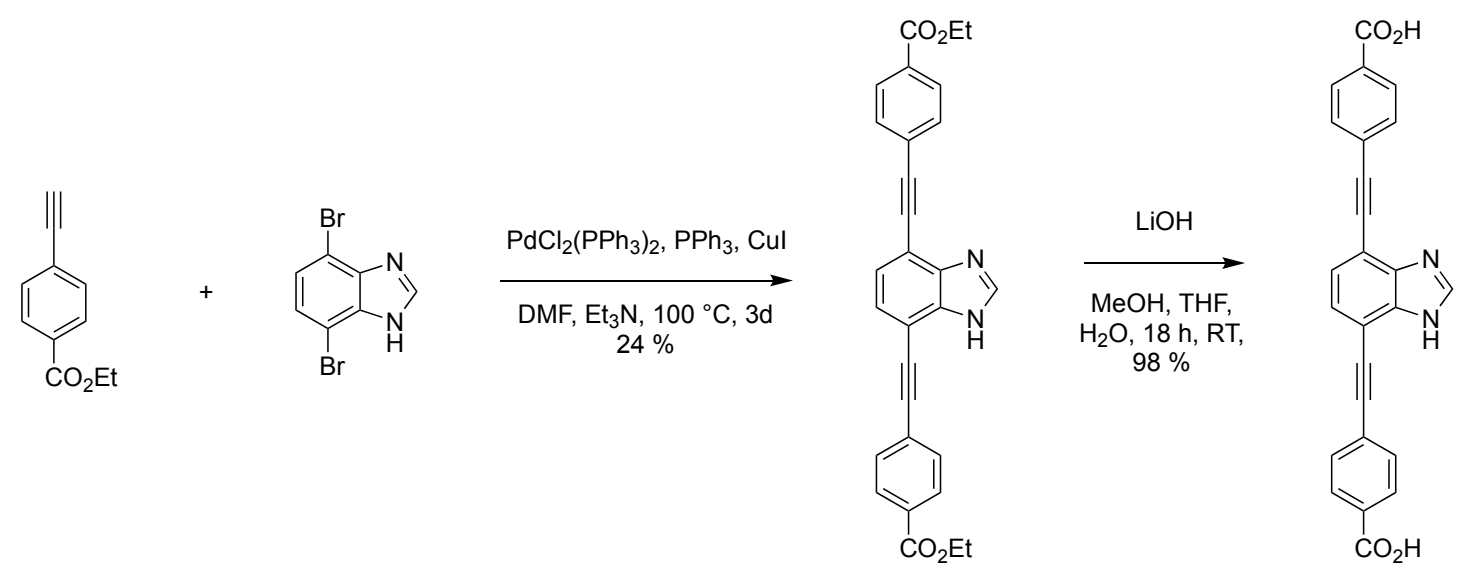

Scheme S2. Synthetic route for AC-BZI.

\section{Steady-State and Time-resolved Spectroscopy}

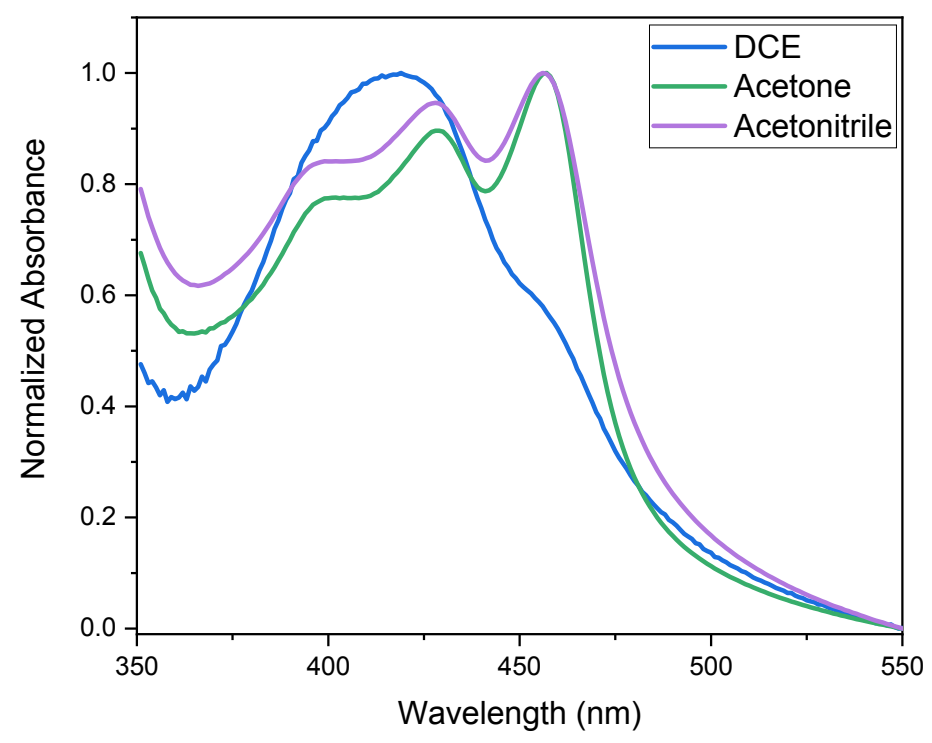

Figure S1. Normalized absorbance spectra of AC-TDZ in dichloroethane, acetone, and acetonitrile. 


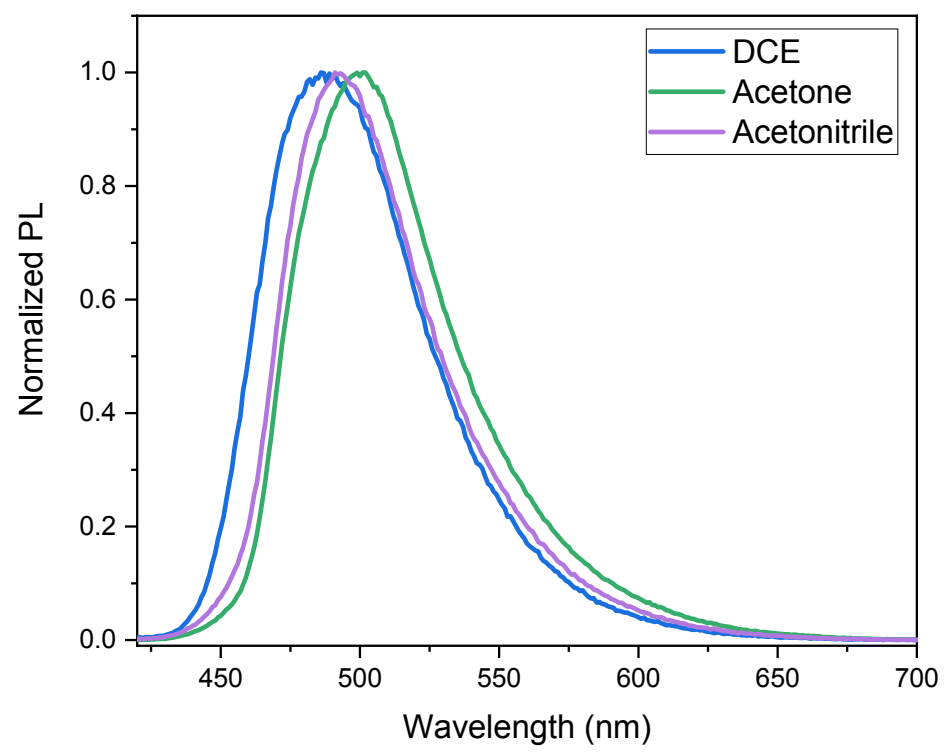

Figure S2. Normalized emission spectra of AC-TDZ in dichloroethane, acetone, and acetonitrile.
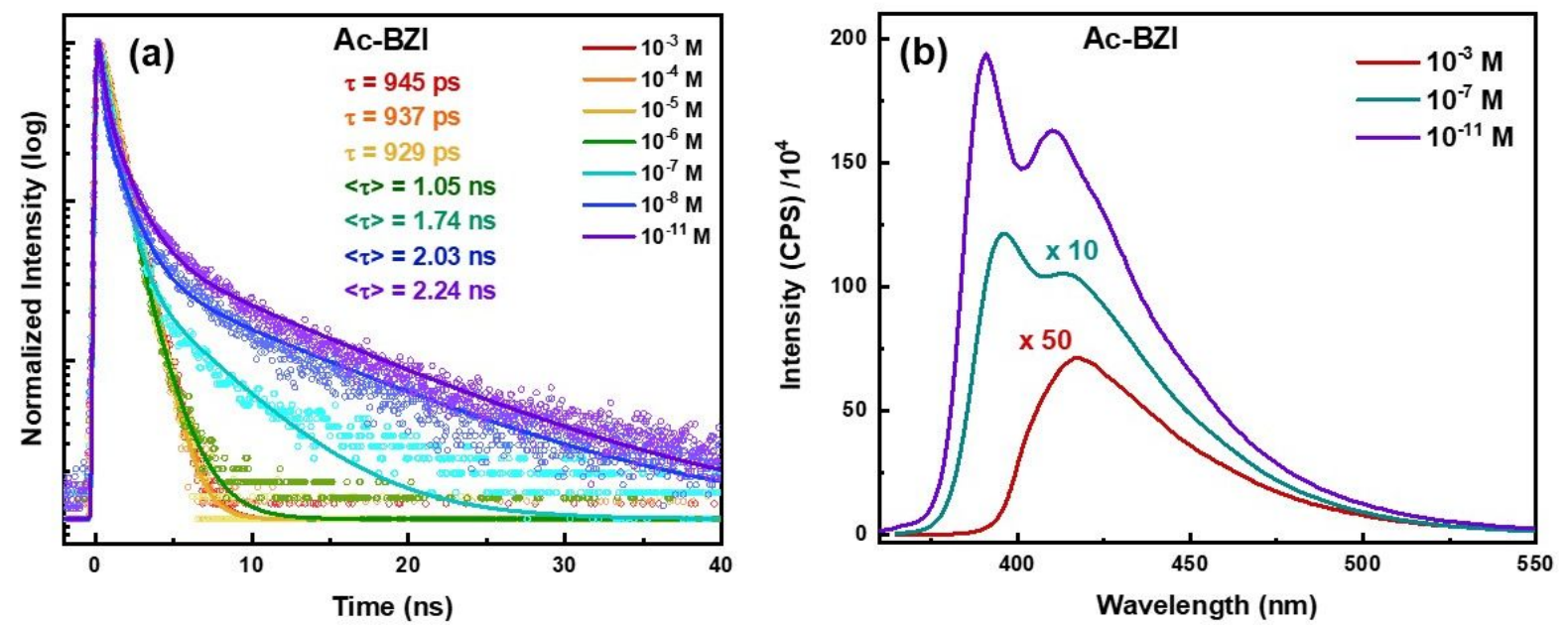

Figure S3. TCSPC for ACBZI at different concentrations in DMSO (a). Emission spectra for ACBZI at different concentrations DMSO. 


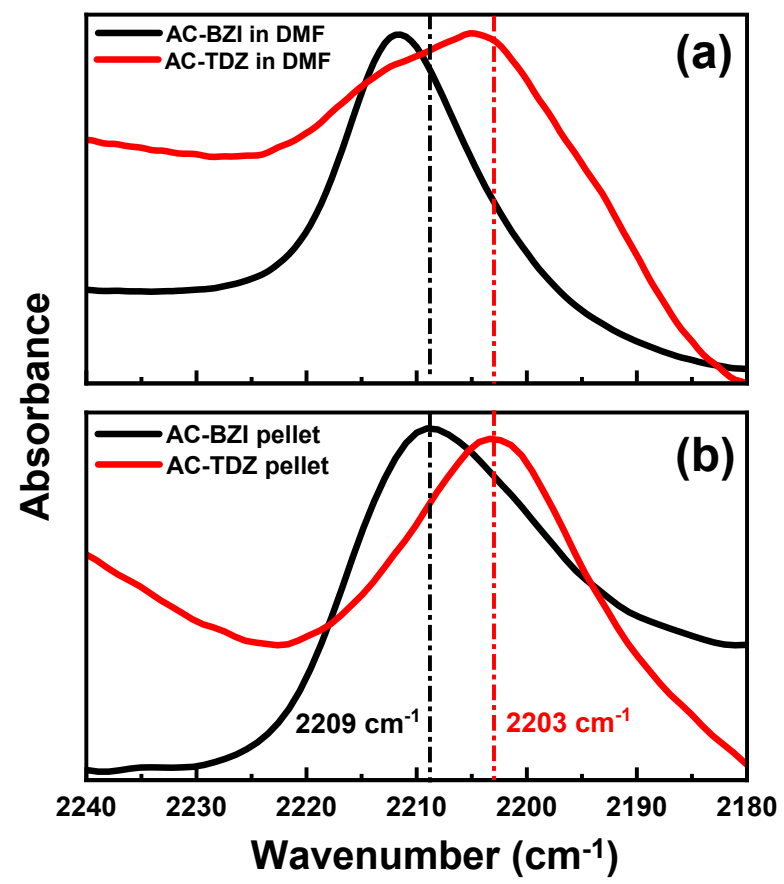

Figure S4. FT-IR spectra of AC-TDZ and AC-BZI in DMF (a), and in a KBr pellet (b)

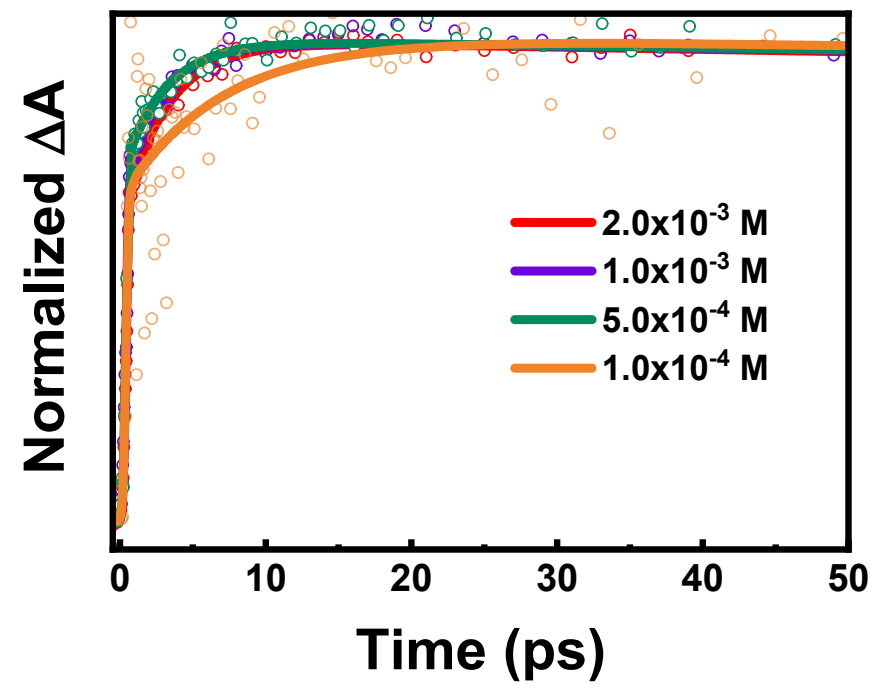

Figure S5. The fs-IR normalized kinetic traces at early times for AZ-TDZ at different concentrations. 


\section{Time-Dependent Density Functional Theory Calculations}

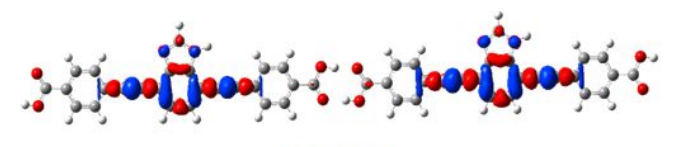

AC-BZI

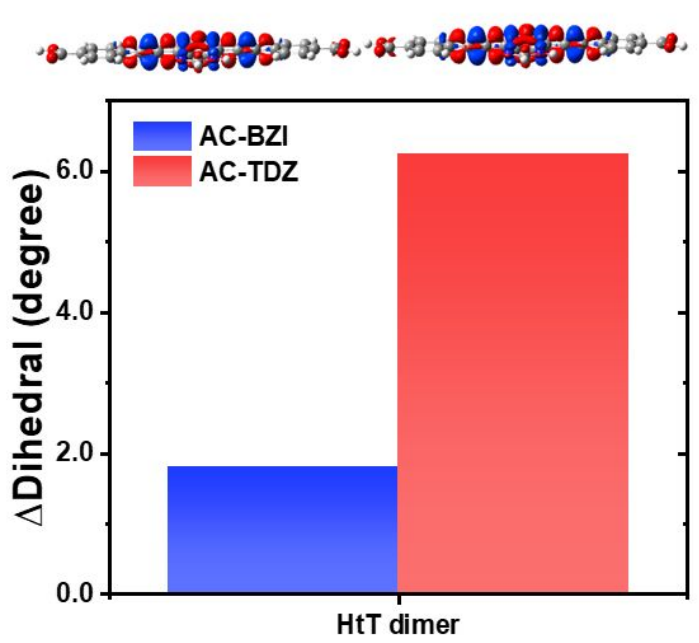

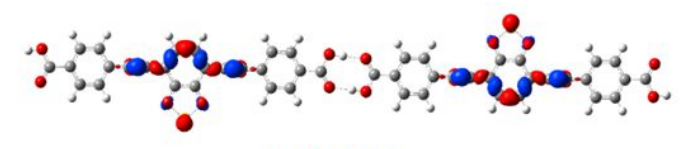

AC-TDZ
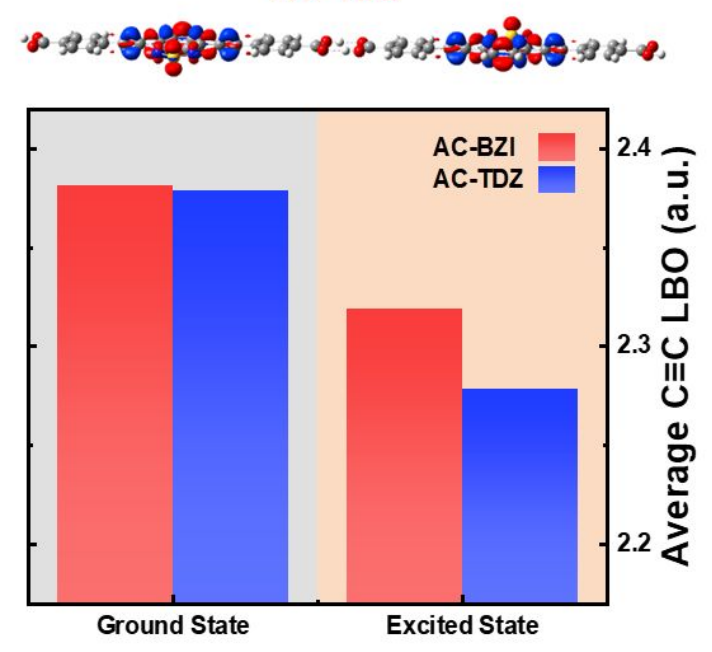

Figure S6. Optimized structures showing electron density changes (blue $=$ loss $/$ red $=$ gain) upon transition to the excited state, change in the dihedral angle, and Laplacian bond order for AC-TDZ and AC-BZI head-to-tail dimers in the ground and excited states. Level of theory: CAM-B3LYP/6$311++\mathrm{G}(\mathrm{d}, \mathrm{p})$; IEFPCM: DMSO.

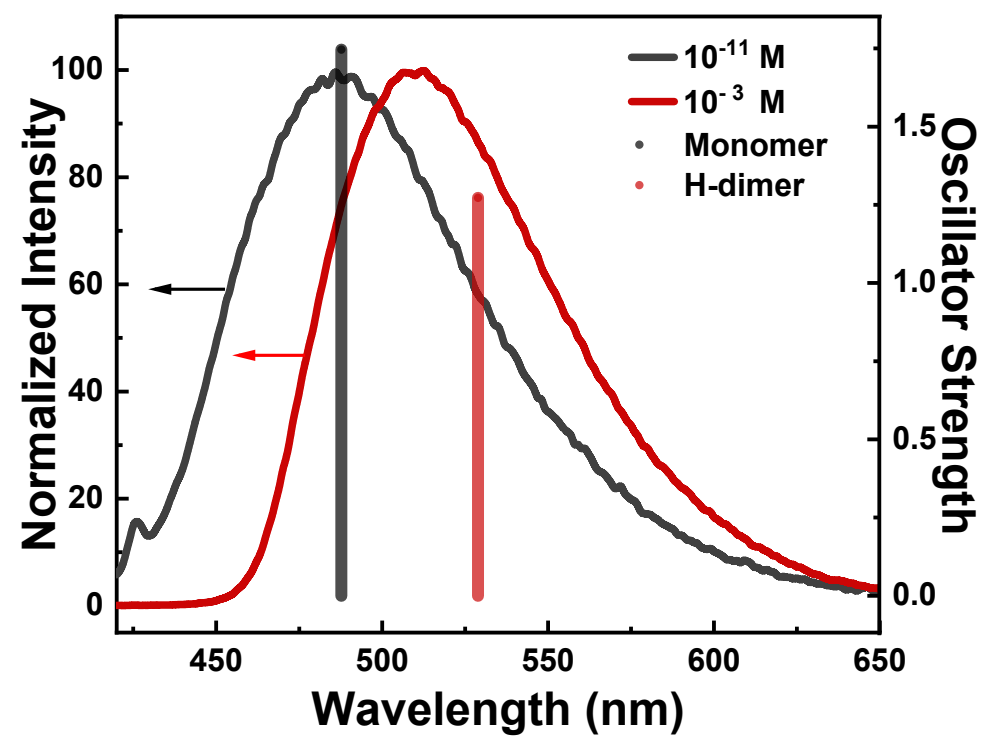

Figure S7. Calculated electronic transitions compared to the experimental PL spectra for ACTDZ monomer and H-dimer. Level of theory: CAM-B3LYP/6-311++G(d,p); IEFPCM: DMSO. 


\section{NMR Molecular Characterization}

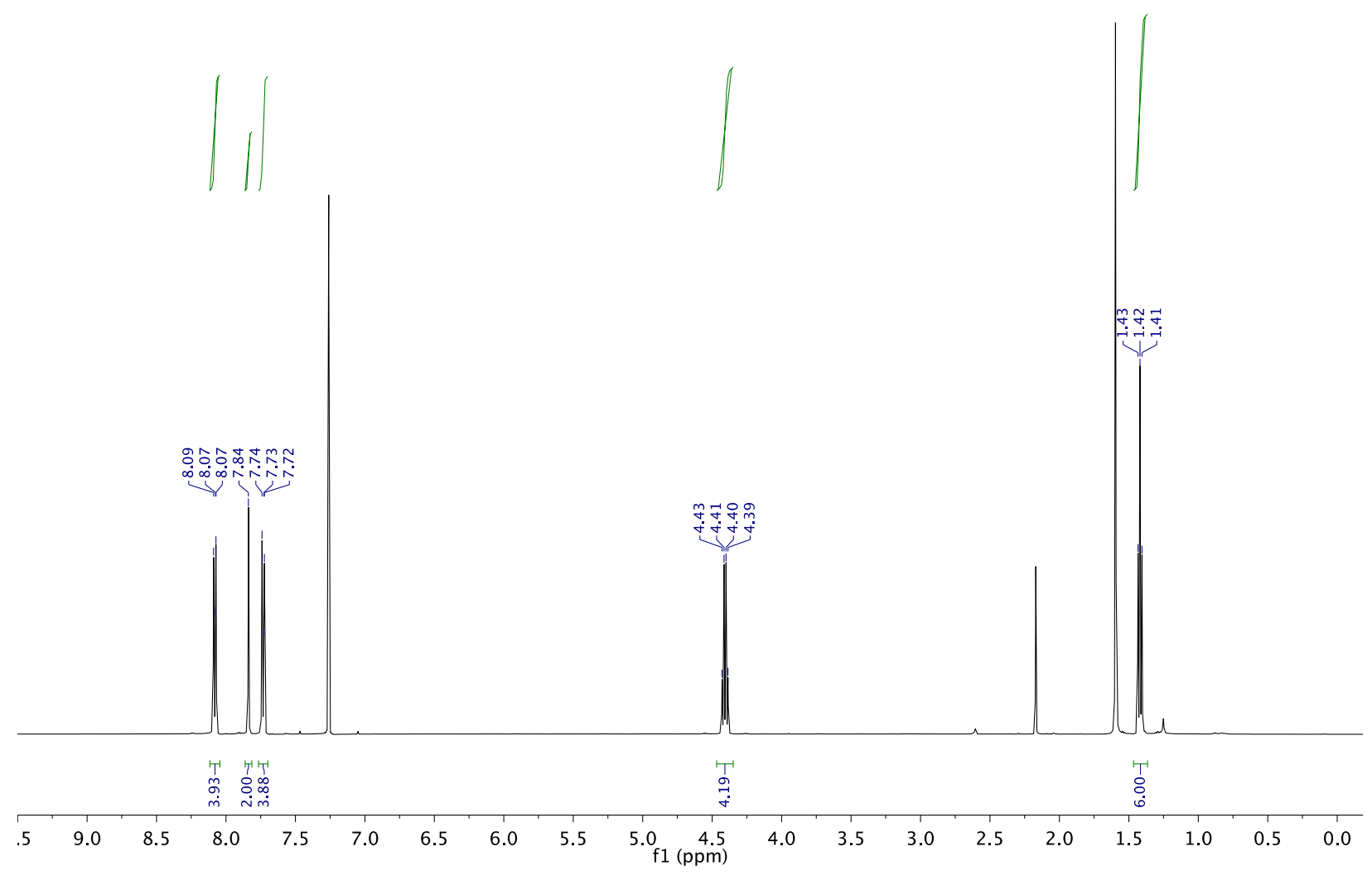

Figure S8. ${ }^{1} \mathbf{H}$ NMR spectra of diethyl 4,4'-(benzo[c][1,2,5]thiadiazole-4,7-diylbis(ethyne-2,1diyl))dibenzoate $\left(500 \mathrm{MHz}, \mathrm{CDCl}_{3}\right)$. 


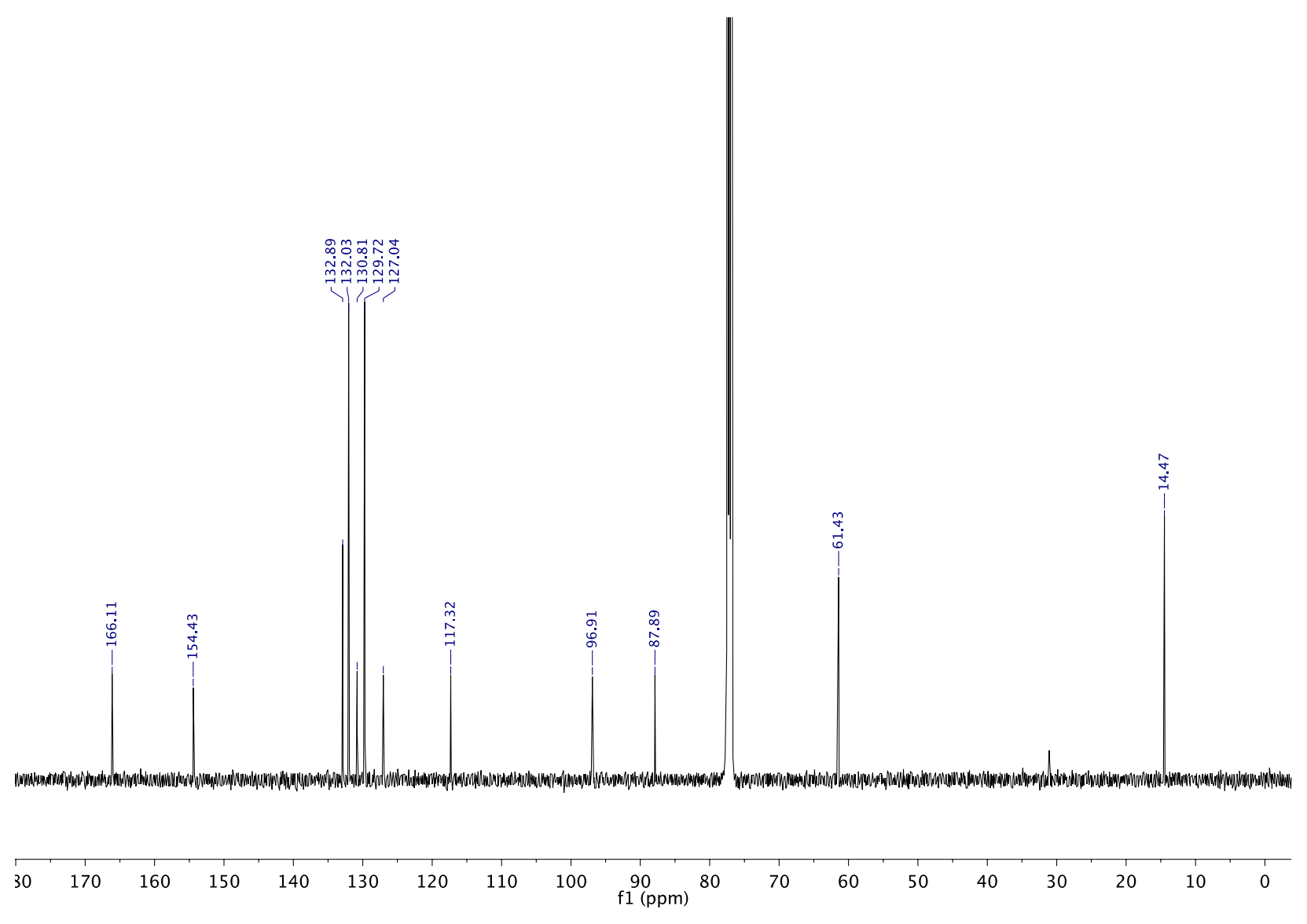

Figure S9. ${ }^{13}$ C NMR spectra of diethyl 4,4'-(benzo[c][1,2,5]thiadiazole-4,7-diylbis(ethyne-2,1diyl))dibenzoate (126 MHz, $\left.\mathrm{CDCl}_{3}\right)$. 


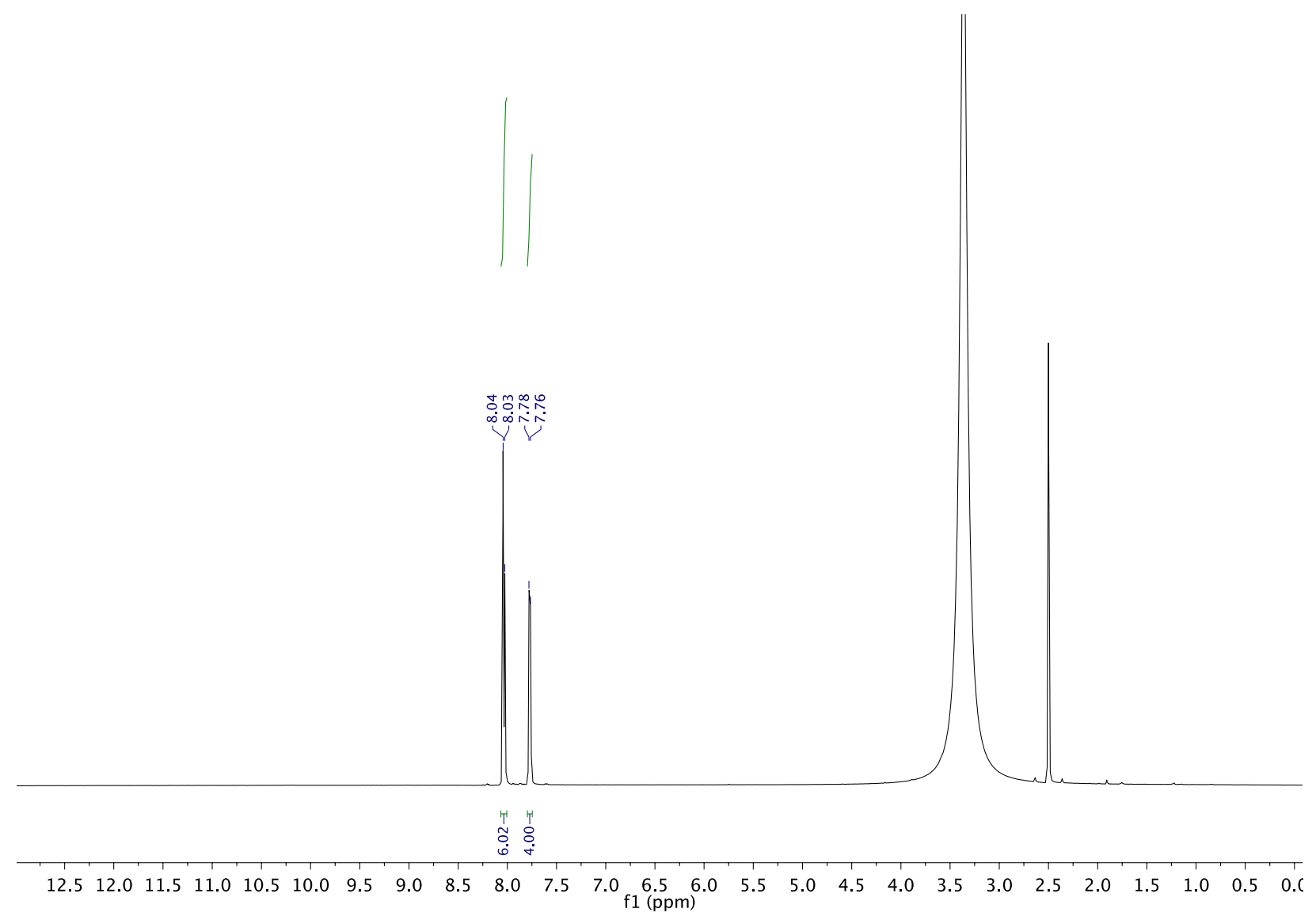

Figure S10. ${ }^{1} \mathbf{H}$ NMR spectra of 4,4'-(benzo[c][1,2,5]thiadiazole-4,7-diylbis(ethyne-2,1diyl))dibenzoic acid (500 MHz, DMSO- $\left.d_{6}\right)$. 

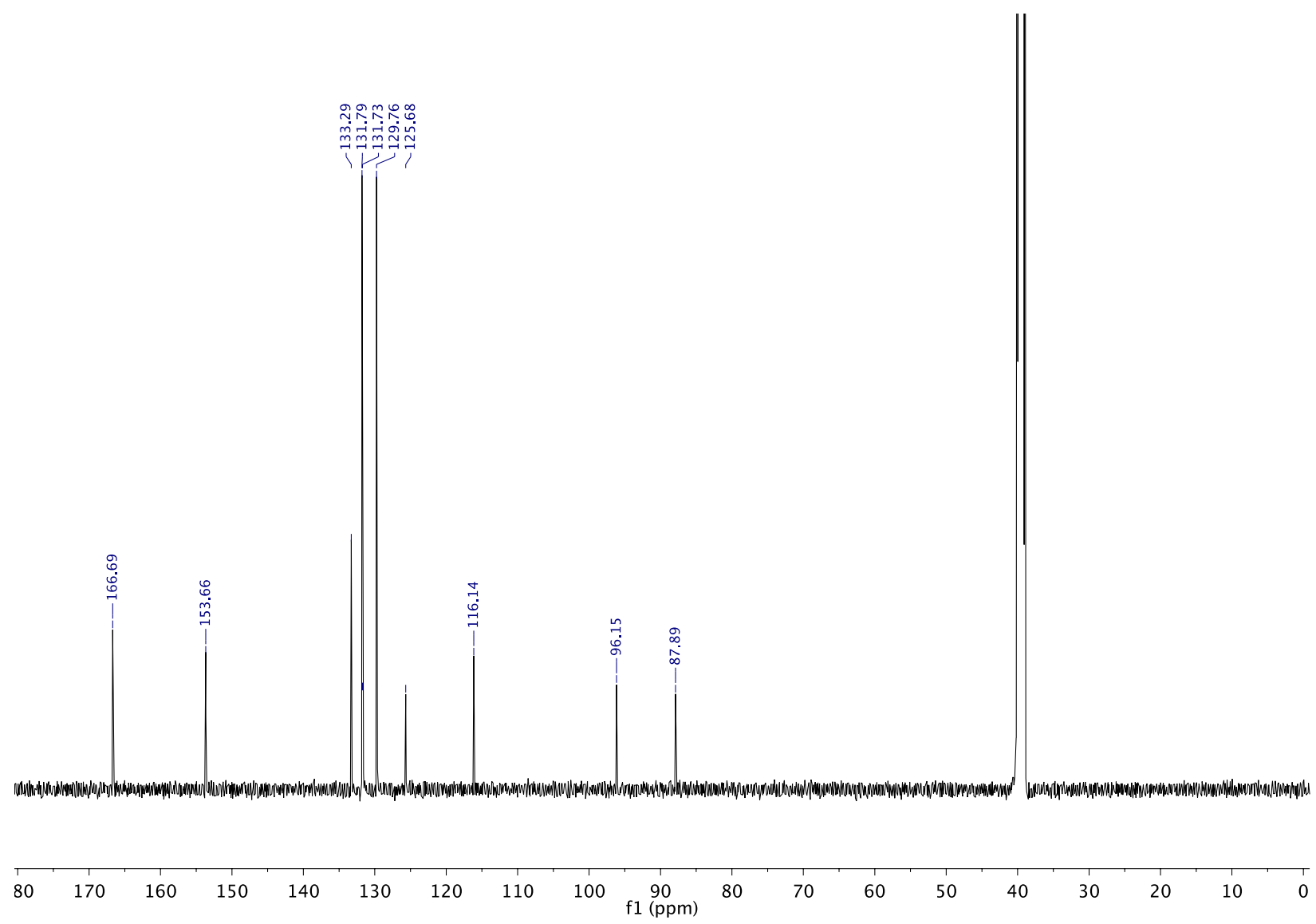

Figure S11. ${ }^{13} \mathbf{C}$ NMR spectra of 4,4'-(benzo[c][1,2,5]thiadiazole-4,7-diylbis(ethyne-2,1diyl))dibenzoic acid (126 MHz, DMSO- $\left.d_{6}\right)$. 


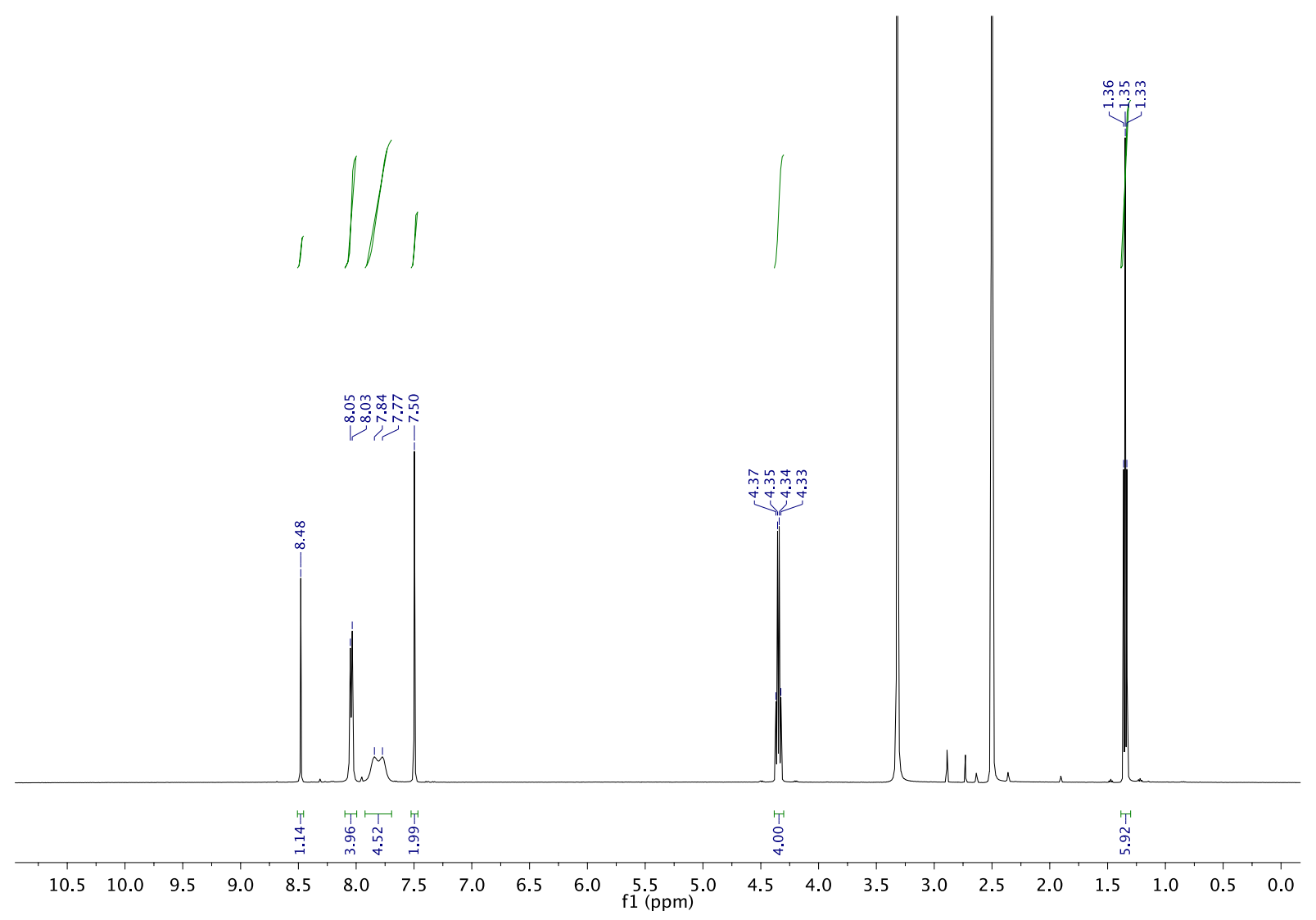

Figure S12. ${ }^{1} \mathbf{H}$ NMR spectra of diethyl 4,4'-((1H-benzo[d]imidazole-4,7-diyl)bis(ethyne-2,1diyl))dibenzoate ( $\left.\mathrm{MHz}, \mathrm{DMSO}-d_{6}\right)$. 


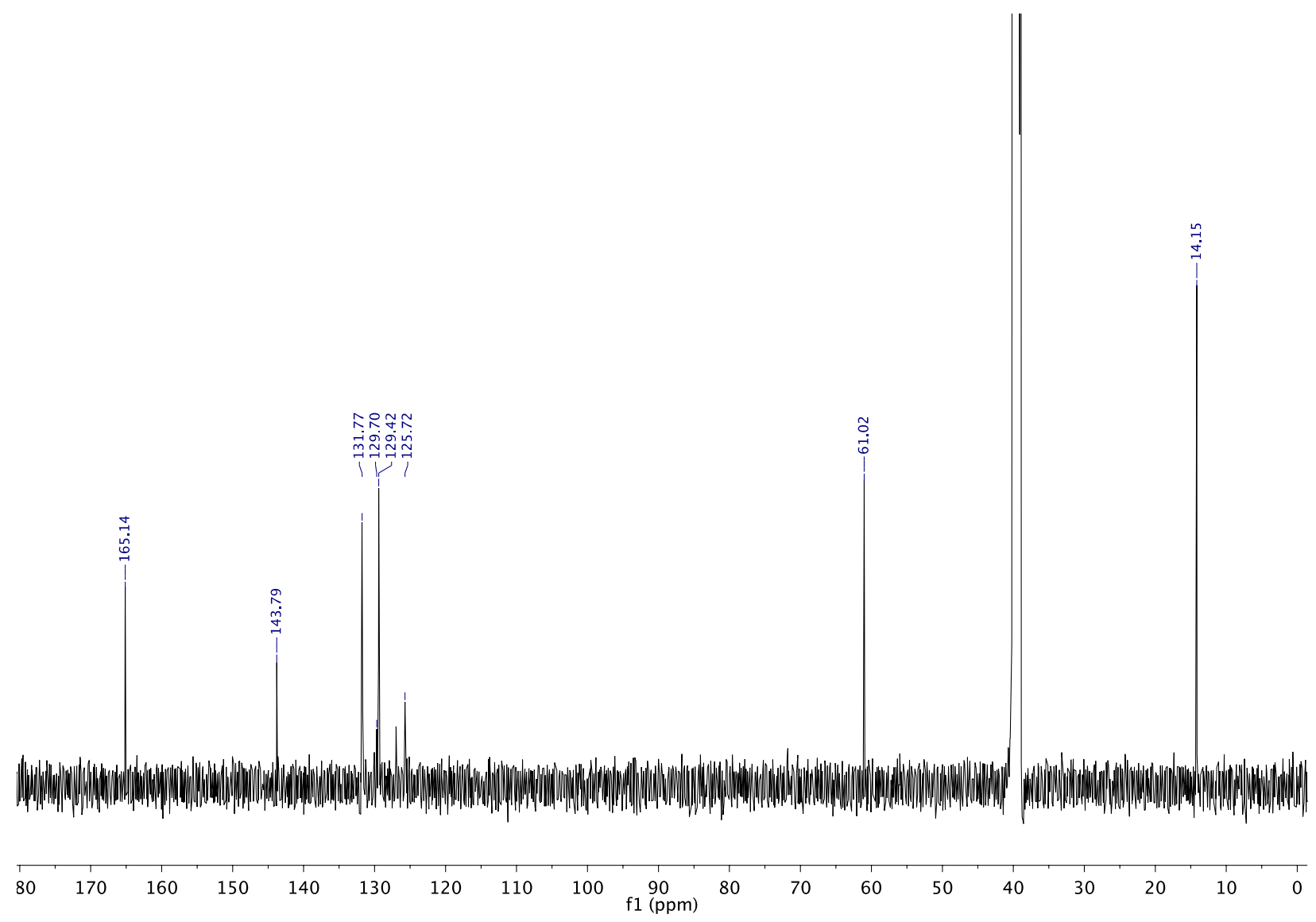

Figure S13. ${ }^{13}$ C NMR spectra of diethyl 4,4'-((1H-benzo[d]imidazole-4,7-diyl)bis(ethyne-2,1diyl))dibenzoate (126 MHz, DMSO- $\left.d_{6}\right)$. 


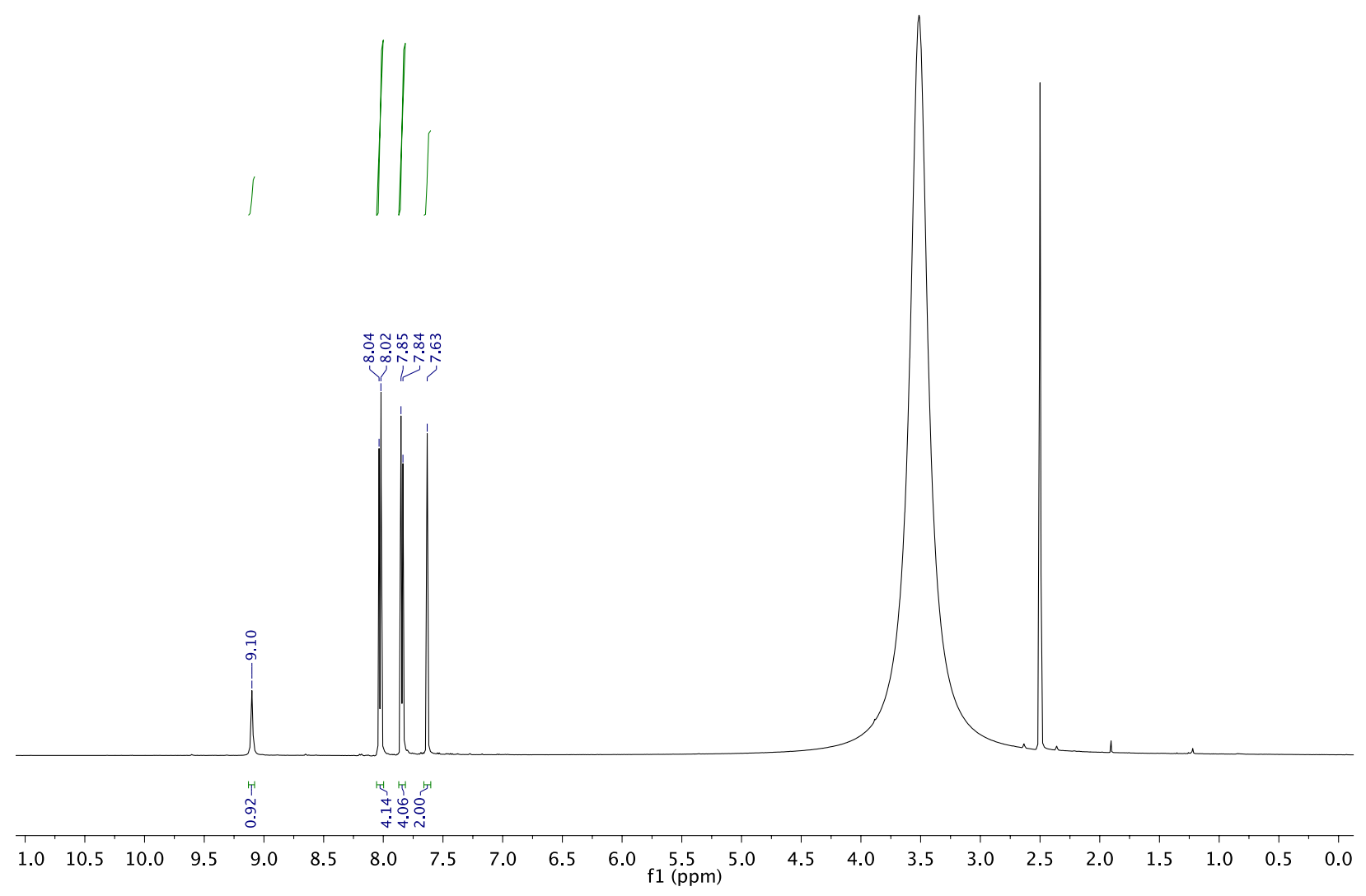

Figure S14. ${ }^{1} \mathbf{H}$ NMR spectra of 4,4'-((1H-benzo[d]imidazole-4,7-diyl)bis(ethyne-2,1diyl))dibenzoic acid (500 MHz, DMSO- $\left.d_{6}\right)$. 


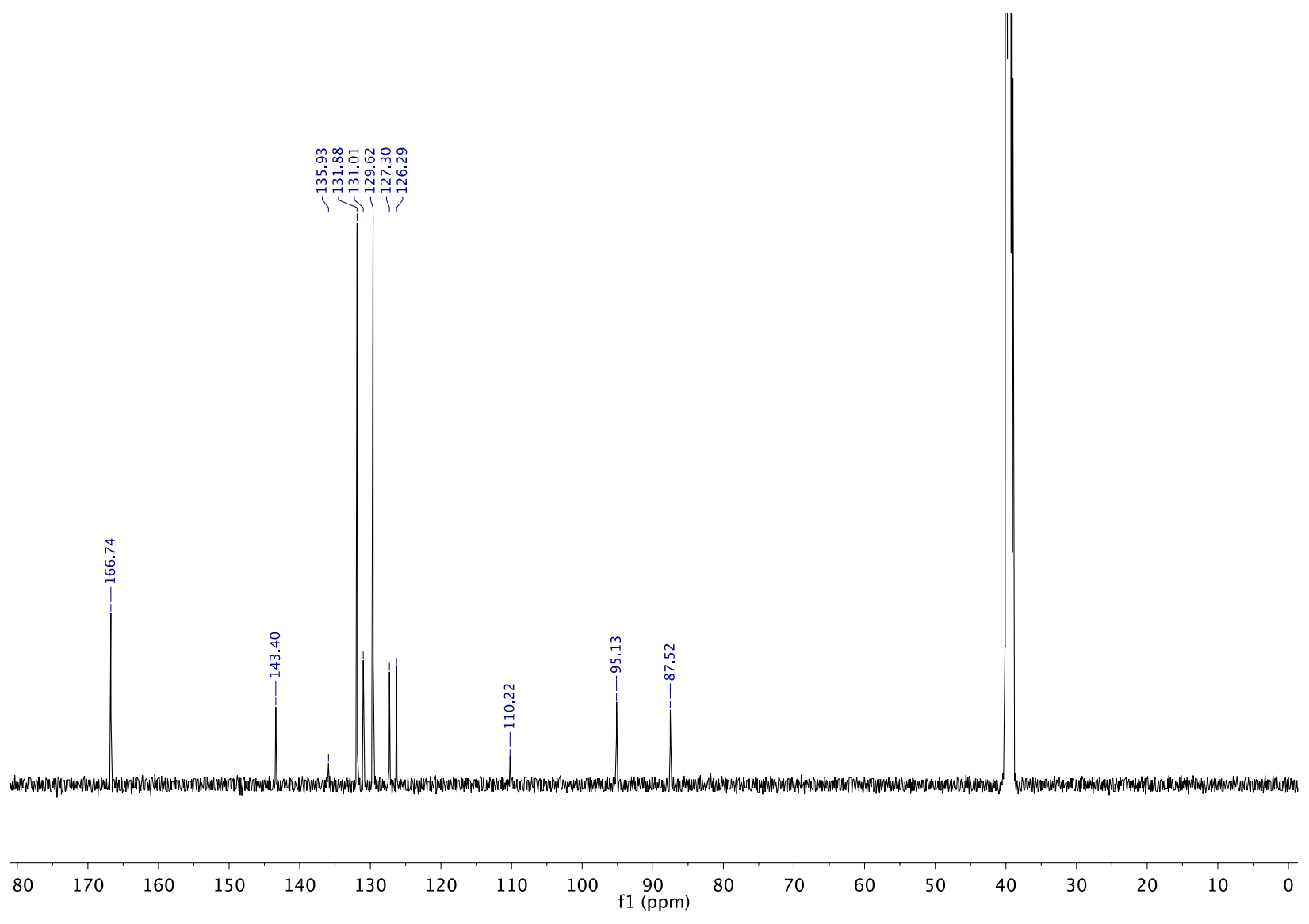

Figure S15. ${ }^{13} \mathrm{C}$ NMR spectra of 4,4'-((1H-benzo[d]imidazole-4,7-diyl)bis(ethyne-2,1diyl))dibenzoic acid (126 MHz, DMSO- $\left.d_{6}\right)$. 